\title{
Persistence of deterrent larval tracks in Coccinella septempunctata, Cycloneda limbifer and Semiadalia undecimnotata (Coleoptera: Coccinellidae)
}

\author{
ZDENĚK RŮŽIČKA \\ Institute of Entomology, Academy of Sciences, Branišovská 31, 37005 České Budějovice, Czech Republic; e-mail: \\ ruzicka@entu.cas.cz
}

\begin{abstract}
Key words. Coccinellidae, Coccinella septempunctata, Cycloneda limbifer, Semiadalia undecimnotata, Chrysopidae, Chrysopa oculata, Chrysopa perla, aphid predators, larval tracks, deterrent secretion, pheromones, semiochemicals, persistence, oviposition, intraspecific effects, interspecific effects
\end{abstract}

\begin{abstract}
The persistence of oviposition-deterring effects of coccinellid and chrysopid larval tracks on females of three aphidophagous coccinellid species was compared. One month old tracks of first instars of the coccinellid Cycloneda limbifer Casey deterred conspecific females from oviposition in choice tests with clean and contaminated substrates. Intraspecific effect of larval tracks in Semiadalia undecimnotata Schneider was statistically significant after 10 days. Although fresh tracks of conspecific first instars effectively deterred females in both tested populations of Coccinella septempunctata L., deterrent effects disappeared when tracks of larvae were only one day old. However, females of $C$. septempunctata laid fewer eggs on sites with 10 days old tracks of Chrysopa oculata Say or sites with one month old tracks of Chrysopa perla (L.) first instars than on clean sites. In contrast to females of $C$. septempunctata and $S$. undecimnotata, C. limbifer females left significantly more faecal spots on clean sites than on sites with 5-30 days old tracks of conspecific first instars. This indicates that sites with tracks of larvae can also effectively repel conspecific females of some coccinellid species from searching.
\end{abstract}

\section{INTRODUCTION}

Oviposition-deterring semiochemicals in the tracks of larvae are most likely to be the main factor causing spacing out of aphidophagous predators. The intensity of deterrent effects depends on the density of larval tracks (Růžička, 1997a). The longer the oviposition deterring semiochemicals persist on substrates walked over by larvae, the more effective the oviposition deterrence.

Intraspecific oviposition-deterrence of larval tracks of predators have been discovered in green lacewings (Růžička, 1994). Similar effects of larval tracks were also described in many ladybird species, Coccinella septempunctata L. (Rủžička, 1997b), Adalia bipunctata (L.) (Doumbia et al., 1998), Harmonia axyridis Pallas (Yasuda et al., 2000), Cycloneda limbifer Casey and Semiadalia undecimnotata (Schneider) [- Ceratomegilla undecimnotata (Schneider)] (Růžička, 2001). Oviposition-deterring substance(s) (ODS) in tracks of chrysopid larvae are soluble in chloroform and water (Rủžička, 1994). ODS of coccinellid larvae are chloroform soluble (Doumbia et al., 1998). Females of these predators prefer oviposition on the undersides of leaves, where eggs, hatching larvae and their tracks are better protected from precipitation and solar radiation. C. limbifer and $S$. undecimnotata lay significantly fewer eggs on sites with fresh larval tracks of heterospecific coccinellids than on clean sites (Růžička, 2001). C. septempunctata even avoids oviposition on sites with tracks of chrysopid larvae (Růžička, 1997b, 2001).

Some attention has been paid already to the persistence of intraspecific effects of larval tracks in chrysopids and coccinellids. Oviposition-deterring effects of tracks left by first instar larvae of the chrysopid $C$. oculata persisted in the open air for at least two weeks, and females laid significantly more eggs on clean papers than on papers, which were enclosed after contamination in Petri dishes for 150 days (Rủžička, 1997a). In a similar choice test, the number of eggs laid by C. septempunctata on substrates with one day old tracks of conspecific first instars and on clean substrates did not differ (Růžička, 1997b). In contrast, $A$. bipunctata laid significantly fewer eggs in a Petri dish with 10 days old tracks of conspecific fourth instars than in the control Petri dish (Hemptinne at al., 2001). Although data on persistence of intraspecific effects of larval tracks indicate differences between coccinellid species, great differences between experimental designs of both studies do not enable reliable rating. Besides, different instars are unlikely to leave equal amounts of ODS in their tracks (Ri̊žička, 1997b).

In this study, for the first time, the persistence of intraspecific oviposition-deterring effects of larval tracks was compared between different species of predators. The effects were investigated in the aphidophagous coccinellids C. limbifer, S. undecimnotata and C. septempunctata. The persistence of oviposition-deterring larval tracks of prey competing aphidophagous species from other taxa may also play an important role in coccinellid spacing (Rủžička, 1997b, 2001). Therefore, the persistence of effects of conspecific larval tracks in C. septempunctata was also compared with that of larval tracks of the chrysopids C. oculata and C. perla. 
TABLE 1. Mean number (per replicate) \pm SE of eggs laid by coccinellid females on clean substrates (-) and on substrates with tracks $(+)$ of conspecific first instar larvae in choice tests after different periods from exposure to larvae. 10 females of each species were tested in ten replicates. ${ }^{* *}=\mathbf{P}<0.01 ; *=\mathrm{P}<0.05 ; \mathrm{ns}=$ not significantly different $(\mathrm{P} \geq 0.05) .{ }^{\text {a) }} \mathrm{n}=20$ replicates.

\begin{tabular}{|c|c|c|c|c|c|c|c|c|c|c|c|c|}
\hline \multirow{2}{*}{$\frac{\text { Species }}{\text { Population }}$} & \multicolumn{3}{|c|}{ Cycloneda limbifer } & \multicolumn{3}{|c|}{ Semiadalia undecimnotata } & \multicolumn{6}{|c|}{ Coccinella septempunctata } \\
\hline & & & & & & & & Louny & & & Boršov & \\
\hline \multirow{2}{*}{$\begin{array}{l}\text { Blank } \\
\text { test }\end{array}$} & - & - & & - & - & & - & - & & - & - & \\
\hline & $209 \pm 20$ & $204 \pm 29$ & ns & $156 \pm 20$ & $156 \pm 25$ & $\mathrm{~ns}$ & $231 \pm 13$ & $212 \pm 20$ & ns & $209 \pm 29$ & $192 \pm 28$ & ns \\
\hline $\begin{array}{l}\text { Tracks } \\
\text { old days }\end{array}$ & + & - & & + & - & & + & - & & + & - & \\
\hline 0 & $33 \pm 13$ & $200 \pm 21$ & $* *$ & $49 \pm 20$ & $180 \pm 27$ & * & $47 \pm 15$ & $257 \pm 31$ & $* *$ & $208 \pm 32$ & $367 \pm 30$ & * \\
\hline 1 & $37 \pm 21$ & $287 \pm 29$ & $* *$ & $38 \pm 17$ & $174 \pm 17$ & $* *$ & $122 \pm 26$ & $177 \pm 25$ & $\mathrm{~ns}$ & $179 \pm 25$ & $237 \pm 27$ & ns \\
\hline 5 & $83 \pm 13$ & $236 \pm 23$ & ** & $121 \pm 15$ & $192 \pm 20$ & * a) & $165 \pm 21$ & $176 \pm 11$ & ns & $159 \pm 25$ & $197 \pm 22$ & ns \\
\hline 10 & $80 \pm 14$ & $254 \pm 32$ & $* *$ & $71 \pm 14$ & $151 \pm 22$ & * & $153 \pm 15$ & $152 \pm 20$ & $\mathrm{~ns}$ & $282 \pm 31$ & $264 \pm 33$ & $\mathrm{~ns}$ \\
\hline 30 & $94 \pm 16$ & $176 \pm 20$ & $*$ & $97 \pm 29$ & $120 \pm 21$ & $\mathrm{~ns}$ & & & & & & \\
\hline 90 & $212 \pm 15$ & $226 \pm 18$ & ns & $210 \pm 19$ & $200 \pm 36$ & $\mathrm{~ns}$ & & & & & & \\
\hline 180 & $222 \pm 22$ & $208 \pm 21$ & ns & $222 \pm 23$ & $172 \pm 23$ & ns & & & & & & \\
\hline 360 & $204 \pm 19$ & $209 \pm 16$ & $\mathrm{~ns}$ & $186 \pm 21$ & $208 \pm 22$ & $\mathrm{~ns}$ & & & & & & \\
\hline 720 & $100 \pm 11$ & $133 \pm 8$ & $*$ & $147 \pm 22$ & $206 \pm 21$ & $\mathrm{~ns}$ & & & & & & \\
\hline 1100 & $198 \pm 20$ & $164 \pm 19$ & ns & $253 \pm 24$ & $255 \pm 29$ & $\mathrm{~ns}$ & & & & & & \\
\hline
\end{tabular}

\section{MATERIALS AND METHODS}

\section{Insects}

Experiments were performed on Cycloneda limbifer Casey (origin in Cuba), Semiadalia undecimnotata (Schneider) [= Ceratomegilla undecimnotata (Schneider)] (origin in North Bohemia, Czech Republic), Chrysopa oculata Say (origin in Nova Scotia, Canada) and Chrysopa perla (L.) (origin in South Bohemia, Czech Republic) from cultures maintained in the laboratory for periods greater than one year. Because several attempts to establish a vigorous long-term laboratory stock culture of Coccinella septempunctata from local populations have failed, tests were carried out with insects collected after the hibernation and with larvae and adults of two following generations reared in the insectary. Oviposition choice tests with this species were limited accordingly. One population of $C$. septempunctata was collected at Boršov near České Budějovice (South Bohemia), the other at Raná near Louny (North Bohemia).

\section{Experimental design}

In previous tests with coccinellids and chrysopids, substrates became deterrent after short exposures to conspecific larvae The chrysopid $C$. oculata laid, in choice tests, significantly more eggs on clean papers when the other substrate was exposed, prior to the test, to first instars for only 15 minutes (Růžička, 1997a). The effect was greater when larvae were present for four hours, and further prolongation of larval presence did not increase the deterrent effect.

Standard oviposition choice test method was adopted from previous studies (Růžička, 1997b, 2001). The oviposition arena consisted of two paper strips, one clean and one with larval tracks, which were on the bottom of a cylindrical cage $18 \mathrm{~cm}$ in diameter and $10 \mathrm{~cm}$ high. Prior to the test, one of the strips was exposed for four hours to 40 unfed first instar coccinellid or chrysopid in a Petri dish $20 \mathrm{~cm}$ in diameter. Strips with tracks of coccinellid or chrysopid larvae were provided to coccinellid females for oviposition after different periods of storage in the open air and room temperature $22 \pm 4^{\circ} \mathrm{C}$. Clean and contaminated strips were stored simultaneously for the same period in order to ensure equal exposure of both substrates to all abiotic factors during the storage. Water and aphids were available to females during the tests, Aphis fabae Scopoli for Cycloneda limbifer and Acyrthosiphon pisum Harris for Semiadalia undecimnotata. Ten coccinellid females were put in the cage. Room temperature was $24 \pm 2^{\circ} \mathrm{C}$. The relative humidity was $40 \pm 10 \%$. The light source was two $40 \mathrm{~W}$, white fluorescent tubes $60 \mathrm{~cm}$ above the cage. Each test lasted 20 hours and had ten replicates.

\section{Statistical analysis}

Numbers of eggs, egg batches and faecal spots on clean substrates and substrates with tracks of first instars were compared with Wilcoxon paired sample tests (two-tailed P value).

\section{RESULTS}

\section{Persistence of intraspecific effects of larval tracks on oviposition}

Strips with tracks of $C$. limbifer larvae deterred conspecific females for up to 30 days of the storage (Table 1). Deterrent effect of substrates with 720 days old tracks was apparently incidental. Numbers of egg batches on substrates in this test did not differ (Table 2). S. undecimnotata avoided oviposition at sites with 10 days old tracks of conspecific larvae (Table 1). However, only paper strips with fresh tracks of first instars effectively deterred conspecific females from oviposition in both tested populations of $C$. septempunctata (Table 1). Differences between the number of eggs oviposited on substrates with and without larval tracks were similar to differences between number of egg batches laid on these substrates by females in each coccinellid species (Tables 1 and 2).

\section{Changes of nonspecific repellent effects of larval tracks on conspecific females}

Differences between the total number of faecal spots of females on clean substrates and substrates with larval tracks were statistically significant in four consequent tests with the coccinellid C. limbifer. Females left more 
TABLE 2. Mean number (per replicate) \pm SE of egg batches laid by coccinellid females on clean substrates (-) and on substrates with tracks $(+)$ of conspecific first instar larvae in choice tests after different periods from exposure to larvae. 10 females of each species were tested in ten replicates. ${ }^{*}=\mathrm{P}<0.01 ; *=\mathrm{P}<0.05 ; \mathrm{ns}=$ not significantly different $(\mathrm{P} \geq 0.05) .{ }^{\text {a) }} \mathrm{n}=20$ replicates.

\begin{tabular}{|c|c|c|c|c|c|c|c|c|c|c|c|c|}
\hline \multirow{2}{*}{$\frac{\text { Species }}{\text { Population }}$} & \multicolumn{3}{|c|}{ Cycloneda limbifer } & \multicolumn{3}{|c|}{ Semiadalia undecimnotata } & \multicolumn{6}{|c|}{ Coccinella septempunctata } \\
\hline & & & & & & & & Louny & & & Boršov & \\
\hline \multirow{2}{*}{$\begin{array}{l}\text { Blank } \\
\text { test }\end{array}$} & - & - & & - & - & & - & - & & - & - & \\
\hline & $12.8 \pm 1.3$ & $12.6 \pm 1.6$ & ns & $11.6 \pm 1.5$ & $11.5 \pm 1.9$ & ns & $7.6 \pm 0.4$ & $7.6 \pm 0.9$ & ns & $6.5 \pm 0.8$ & $5.5 \pm 0.7$ & ns \\
\hline $\begin{array}{l}\text { Tracks } \\
\text { old days }\end{array}$ & + & - & & + & - & & + & - & & + & - & \\
\hline 0 & $1.5 \pm 0.4$ & $10.3 \pm 1.2$ & $* *$ & $4.4 \pm 1.7$ & $13.0 \pm 1.8$ & * & $1.7 \pm 0.5$ & $10.2 \pm 1.0$ & $* *$ & $5.3 \pm 0.7$ & $9.9 \pm 0.7$ & $*$ \\
\hline 1 & $2.6 \pm 1.3$ & $17.7 \pm 2.1$ & $* *$ & $3.4 \pm 1.3$ & $12.4 \pm 1.3$ & $* *$ & $4.5 \pm 0.8$ & $8.2 \pm 1.5$ & $\mathrm{~ns}$ & $5.3 \pm 0.6$ & $7.5 \pm 0.8$ & ns \\
\hline 5 & $5.4 \pm 0.7$ & $16.2 \pm 1.5$ & $* *$ & $9.4 \pm 1.2$ & $14.9 \pm 1.3$ & **a) & $7.8 \pm 1.0$ & $9.7 \pm 1.0$ & $\mathrm{~ns}$ & $5.4 \pm 0.6$ & $6.8 \pm 0.7$ & ns \\
\hline 10 & $5.5 \pm 1.0$ & $16.7 \pm 1.9$ & $* *$ & $6.1 \pm 1.2$ & $11.1 \pm 1.7$ & $\mathrm{~ns}$ & $9.5 \pm 1.0$ & $8.9 \pm 1.1$ & $\mathrm{~ns}$ & $7.8 \pm 0.7$ & $7.6 \pm 0.9$ & ns \\
\hline 30 & $6.1 \pm 1.0$ & $12.0 \pm 1.2$ & $*$ & $9.0 \pm 2.2$ & $10.3 \pm 2.0$ & $\mathrm{~ns}$ & & & & & & \\
\hline 90 & $16.8 \pm 1.4$ & $16.7 \pm 1.3$ & $\mathrm{~ns}$ & $17.3 \pm 1.5$ & $15.7 \pm 2.2$ & ns & & & & & & \\
\hline 180 & $16.0 \pm 1.2$ & $14.8 \pm 1.2$ & $\mathrm{~ns}$ & $18.0 \pm 1.3$ & $14.7 \pm 2.3$ & $\mathrm{~ns}$ & & & & & & \\
\hline 360 & $16.9 \pm 1.8$ & $18.7 \pm 1.5$ & $\mathrm{~ns}$ & $14.4 \pm 1.6$ & $14.6 \pm 1.1$ & ns & & & & & & \\
\hline 720 & $10.0 \pm 1.1$ & $12.3 \pm 0.8$ & $\mathrm{~ns}$ & $11.2 \pm 1.7$ & $16.0 \pm 1.5$ & ns & & & & & & \\
\hline 1100 & $21.6 \pm 2.3$ & $18.2+2.2$ & ns & $26.9 \pm 2.9$ & $27.8 \pm 3.2$ & ns & & & & & & \\
\hline
\end{tabular}

faecal spots on clean substrates than on substrates with tracks 5-90 days old (Table 3). However, the number of faecal spots on clean substrates and contaminated substrates were similar in tests with fresh and one day old larval tracks. Females left significantly higher $(P<0.05)$ number of faecal spots on the upper side of substrates with fresh tracks of $C$. limbifer $(47 \pm 3.55)$ than on the upper side of clean substrates $(37.2 \pm 2.92)$. In tests with fresh, 1, 5 and 30 days old larval tracks, the number of faecal spots of $C$. limbifer on the lower sides of contaminated and clean substrates, which females markedly preferred for oviposition, were significantly lower on contaminated $(19.5 \pm 1.28,15.7 \pm 3.77,18.3 \pm 1.8$ and $20.2 \pm 4.37)$ than on clean sites $(27 \pm 4.03,36 \pm 5.4,35.4$ \pm 3.9 and $30.7 \pm 2.36)(\mathrm{P}<0.05, \mathrm{P}<0.01, \mathrm{P}<0.01$ and $\mathrm{P}$ $<0.05$ respectively). S. undecimnotata and C. septempunctata females left similar number of faecal spots on clean substrates and substrates with larval tracks in all tests (Table 3).

\section{Persistence of effects of chrysopid larval tracks on $\boldsymbol{C}$. septempunctata}

Females of $C$. septempunctata from the population collected in North Bohemia laid significantly more eggs on clean sites than on sites with fresh or 10 days old tracks of C. oculata first instars. Females of this coccinellid species also laid more eggs on clean sites than on sites with fresh tracks or 30 days old tracks of Chrysopa perla first instars (Table 4). Moreover, in choice tests with chrysopid tracks, the differences between the number of eggs laid by $C$. septempunctata on clean and contaminated sites were similar to the differences between the number of egg batches (Table 4).

\section{DISCUSSION}

Several studies have shown that the searching behaviour of coccinellid and chrysopid larvae is basically the same, with the search pattern depending on prey density (Banks, 1954, 1955; Dixon, 1959; Bänsch, 1964, 1965). Before the dispersal to distant prey resources, the density of oviposition-deterring tracks of coccinellid larvae is likely to increase particularly near sites where egg batches have been laid and first instars searched for the prey.

Choice tests of this study showed that the persistence of intraspecific oviposition-deterring effects of tracks of first instars can considerably differ between species of aphidophagous coccinellids. While females from two different populations of C. septempunctata decreased oviposition significantly only on sites with fresh tracks, S. undecimnotata avoided oviposition on substrates with 10 days old tracks and $C$. limbifer on those with 30 days old tracks. The period of persistence of oviposition-deterring effects in C. limbifer was even longer than developmental time of larvae. Similar differences between species are likely to occur also in other groups of aphidophagous predators.

Coccinellids responded to ODS of chrysopid larvae rarely. Oviposition-deterring effects of fresh larval tracks of two chrysopid species, C. oculata and C. perla on C. septempunctata females were described earlier (Růžička, 1997b, 2001), but only this study showed that tracks of both chrysopid species deter $C$. septempunctata females for considerably longer time than tracks of conspecific larvae. C. septempunctata reduced oviposition significantly on sites with 10 days old tracks of $C$. oculata larvae and on sites with 30 days old tracks of $C$. perla. These effects are in accord with the presumption that $C$. septempunctata females avoid oviposition on sites where aggressive chrysopid larvae might be present more than on sites with less dangerous conspecifics.

Proportions between the number of eggs on clean and contaminated substrates were similar to proportions between egg batches on the substrates. This offers a possibility of fast and simple evaluation of ovipositiondeterring effects in similar tests. 
TABLE 3. Mean number (per replicate) \pm SE of faecal spots left by coccinellid females on clean substrates (-) and on substrates with tracks $(+)$ of conspecific first instar larvae in choice tests after different periods from exposure to larvae. 10 females of each species were tested in ten replicates. ${ }^{* *}=\mathrm{P}<0.01{ }^{*}=\mathrm{P}<0.05 ; \mathrm{ns}=$ not significantly different $(\mathrm{P} \geq 0.05) .{ }^{\text {a) }} \mathrm{n}=20$ replicates.

\begin{tabular}{|c|c|c|c|c|c|c|c|c|c|}
\hline Species & \multicolumn{3}{|c|}{ Cycloneda limbifer } & \multicolumn{3}{|c|}{ Semiadalia undecimnotata } & \multicolumn{3}{|c|}{ Coccinella septempunctata } \\
\hline Population & & & & & & & & Boršov & \\
\hline \multirow{2}{*}{$\begin{array}{l}\text { Blank } \\
\text { test }\end{array}$} & - & - & & - & - & & - & - & \\
\hline & $71 \pm 6$ & $75 \pm 5$ & ns & $88 \pm 10$ & $85 \pm 8$ & $\mathrm{~ns}$ & $73 \pm 9$ & $76 \pm 11$ & $\mathrm{~ns}$ \\
\hline $\begin{array}{l}\text { Tracks } \\
\text { old days }\end{array}$ & + & - & & + & - & & + & - & \\
\hline 0 & $67 \pm 4$ & $64 \pm 6$ & ns & $101 \pm 9$ & $111 \pm 8$ & ns & $100 \pm 12$ & $98 \pm 10$ & ns \\
\hline 1 & $57 \pm 10$ & $80 \pm 8$ & ns & $70 \pm 12$ & $77 \pm 6$ & ns & $81 \pm 7$ & $98 \pm 10$ & $\mathrm{~ns}$ \\
\hline 5 & $54 \pm 6$ & $87 \pm 5$ & $* *$ & $105 \pm 8$ & $112 \pm 9$ & $\mathrm{~ns}^{\text {a) }}$ & $81 \pm 9$ & $94 \pm 11$ & $\mathrm{~ns}$ \\
\hline 10 & $38+5$ & $61 \pm 3$ & $* *$ & $118 \pm 12$ & $111 \pm 8$ & ns & $96 \pm 10$ & $106 \pm 13$ & ns \\
\hline 30 & $42 \pm 9$ & $69 \pm 8$ & $*$ & $92 \pm 7$ & $95 \pm 9$ & $\mathrm{~ns}$ & & & \\
\hline 90 & $61 \pm 5$ & $74 \pm 3$ & * & $148 \pm 16$ & $160 \pm 11$ & $\mathrm{~ns}$ & & & \\
\hline 180 & $66 \pm 8$ & $70 \pm 7$ & $\mathrm{~ns}$ & $163 \pm 18$ & $162 \pm 15$ & ns & & & \\
\hline 360 & $74 \pm 7$ & $79 \pm 6$ & $\mathrm{~ns}$ & $123 \pm 15$ & $117 \pm 10$ & $\mathrm{~ns}$ & & & \\
\hline 720 & $31 \pm 4$ & $35 \pm 4$ & ns & $125 \pm 9$ & $158 \pm 12$ & $*$ & & & \\
\hline 1100 & $34 \pm 3$ & $36 \pm 3$ & ns & $178 \pm 12$ & $184 \pm 14$ & $\mathrm{~ns}$ & & & \\
\hline
\end{tabular}

Female ability to discriminate between hosts or sites of different qualities is undoubtedly the main precondition of egg spacing. Already, Salt (1934) clearly distinguished between the female ability to discriminate and the ability to refrain from oviposition. Two or more-choice experiments were regularly used to compare effects of sites which might have different suitability for oviposition (Phillips \& Strand, 1994; Růžička, 1994; Yasuda et al., 2000). In choice tests with clean and contaminated substrates exposed, prior to the test, to conspecific larvae for four hours, C. septempunctata avoided oviposition on sites with fresh tracks of first and second instars, but only tracks of second instars deterred females one day later (Růžička, 1997b). In contrast, when A. bipunctata was confined for 3 hours in a Petri dish with only one substrate, previously exposed to conspecific fourth instars for 24 hours, oviposition in dishes with fresh and 10 days old tracks was similar (Hemptinne et al., 2001). Results of earlier confinement experiments, which were designed to study deterrent effects of encounters between females and larvae on oviposition, showed that female ability to withhold egg laying declined with gradual prolongation of their enclosure with larvae (Hemptinne \& Dixon, 1991; Hemptinne et al., 1992). In phytophagous insects, effects of ODS were higher when contaminated substrates were supplied exclusively in confinement tests than simultaneously with clean substrates in choice tests (Anbutsu \& Togashi, 2002), though differences between oviposition rates in both tests were insignificant. All this indicates that experimental design of studies on ODS effects in aphidophagous insects deserves special attention.

Dozens of semiochemicals were determined by chemical analysis in tracks of larvae of the coccinellid $A$. bipunctata (Hemptinne et al., 2001). When information

TABLE 4. Mean number (per replicate) \pm SE of eggs and egg batches laid by Coccinella septempunctata females on clean substrates (-) and on substrates with tracks ( + ) of first instar larvae of Chrysopa oculata and Chrysopa perla in choice tests after different periods from exposure to larvae. 10 females of each species were tested in ten replicates. $\mathbf{P}$ value): $* *=\mathbf{P}<0.01 ; *=\mathbf{P}<0.05$; $\mathrm{ns}=$ not significantly different $(\mathrm{P} \geq 0.05)$.

\begin{tabular}{|c|c|c|c|c|c|c|c|c|c|c|c|c|}
\hline \multirow{4}{*}{$\begin{array}{l}\text { Larvae } \\
\text { Blank } \\
\text { test }\end{array}$} & \multicolumn{6}{|c|}{ Chrysopa oculata } & \multicolumn{6}{|c|}{ Chrysopa perla } \\
\hline & \multicolumn{3}{|c|}{ Eggs } & \multicolumn{3}{|c|}{ Batches } & \multicolumn{3}{|c|}{ Eggs } & \multicolumn{3}{|c|}{ Batches } \\
\hline & - & - & & - & - & & - & - & & - & - & \\
\hline & $217 \pm 32$ & $180 \pm 11$ & $\mathrm{~ns}$ & $9.7 \pm 1.4$ & $6.8 \pm 0.3$ & $\mathrm{~ns}$ & $217 \pm 32$ & $180 \pm 11$ & ns & $9.7 \pm 1.4$ & $6.8 \pm 0.3$ & $\mathrm{~ns}$ \\
\hline $\begin{array}{l}\text { Tracks } \\
\text { old days }\end{array}$ & + & - & & + & - & & + & - & & + & - & \\
\hline 0 & $141 \pm 28$ & $270 \pm 26$ & * & $4.2 \pm 0.8$ & $7.9 \pm 0.6$ & * & $109 \pm 17$ & $203 \pm 28$ & * & $4.9 \pm 0.9$ & $7.9 \pm 1.2$ & $*$ \\
\hline 1 & $187 \pm 29$ & $242 \pm 36$ & $\mathrm{~ns}$ & $5.8 \pm 0.1$ & $7.6 \pm 0.7$ & $\mathrm{~ns}$ & $156 \pm 29$ & $165 \pm 15$ & ns & $4.4 \pm 0.7$ & $5.1 \pm 0.3$ & $\mathrm{~ns}$ \\
\hline 5 & $118 \pm 15$ & $217 \pm 22$ & * & $4.6 \pm 0.8$ & $8.4 \pm 1.1$ & $*$ & $86 \pm 24$ & $133 \pm 22$ & ns & $3 \pm 0.6$ & $4.5 \pm 0.8$ & ns \\
\hline 10 & $108 \pm 14$ & $206 \pm 40$ & * & $3.2 \pm 0.4$ & $6.3 \pm 0.8$ & * & $130 \pm 23$ & $222 \pm 30$ & * & $4.6 \pm 0.9$ & $7.2 \pm 0.9$ & $* *$ \\
\hline 30 & $143 \pm 26$ & $235 \pm 43$ & $\mathrm{~ns}$ & $4.1 \pm 0.6$ & $9.7 \pm 1.9$ & $*$ & $58 \pm 10$ & $148 \pm 9$ & $* *$ & $2.6 \pm 0.4$ & $7.1 \pm 0.6$ & $* *$ \\
\hline
\end{tabular}


on semiochemicals in larval tracks of different coccinellid species will be available, data on the persistence of oviposition-deterring effects may help to identify active compounds, or groups of compounds, which cause species specific oviposition-deterring response in coccinellids (Růžička, 2001). Long persistence of effects of oviposition-deterring tracks of some coccinellids, and perhaps even the use of synthetic ODS in future, may contribute to well-founded evaluation of the impact of these beneficials on aphid population in field experiments.

Yasuda et al. (2000) reported that females of the coccinellid Harmonia axyridis Pallas laid fewer eggs and visited less frequently Vicia faba L. plants with conspecific tracks than plants with tracks of C. septempunctata third instars. The authors suggested that this behaviour may account for why fewer eggs were laid on plants contaminated with conspecific larval tracks. In C. limbifer, in this study, the density of faecal spots left on sites with 5-90 days old conspecific tracks of first instars was also lower than on clean sites, indicating that female spent a longer time on clean sites. However, densities of spots on sites with fresh tracks and clean sites were similar, though the sites with fresh tracks deterred females from oviposition more than sites with older tracks. This indicates that fresh tracks may not deter $C$. limbifer females from searching, in spite of their strong oviposition-deterring effects (Rủžička, 2001). Effects of fresh tracks of conspecific and heterospecific larvae, on the searching behaviour of C. limbifer females, have recently been studied in detail with an automatic video-tracking system (Růžička \& Zemek, in press).

ACKNOWLEDGEMENTS. This research was supported by the grant of the Grant Agency of the Czech Republic, No. 206/00/0809, from the Entomology Institute project Z5007907 (Acad. Sci. CR) and the grant project S5007102 (Grant Agency Acad. Sci. CR). I thank M. Červenská and R. Guttwirthová for their assistance with experiments and cultures of insects.

\section{REFERENCES}

Anbutsu H. \& Togashi K. 2002: Oviposition deterrence associated with larval frass of the Japanese pine sawyer, Monochamus alternatus (Coleoptera: Cerambycidae). J. Insect Physiol. 48: 459-465.

BANKS C.J. 1954: The searching behaviour of coccinellid larvae. Brit. J. Anim. Behav. 2: 37-38.

BANKS C.J. 1955: The behaviour of individual coccinellid larvae on plants. Brit. J. Anim. Behav. 5: 12-24.
BÄNSCH R. 1964: Vergleichende Untersuchungen zur Biologie und Beutefangverhalten aphidivorer Coccinelliden, Chrysopiden und Syrphiden. Zool. Jb. Syst. 91: 271-340.

BÄNSCH R. 1965: On prey seeking behaviour of aphidophagous insects. In: Hodek I. (ed.): Ecology of Aphidophagous Insects. Academia, Prague, pp. 123-128.

DiXon A.F.G. 1959: An experimental study of the searching behaviour of the predatory coccinellid beetle Adalia decempunctata (L.). J. Anim. Ecol. 28: 259-281.

Doumbia M., Hemptinne J.-L. \& Dixon A.F.G. 1998: Assessment of patch quality by ladybirds: role of larval tracks. Oecologia 113: 197-202.

Hemptinne J.-L. \& Drxon A.F.G. 1991: Why ladybirds have generally been so ineffective in biological control? In: Polgár L., Chambers R.J., Dixon A.F.G. \& Hodek I. (eds): Behaviour and Impact of Aphidophaga. SPB Academic Publishing, The Hague, pp. 149-157.

Hemptinne J.-L., Dixon A.F.G. \& Coffin J. 1992: Attack strategy of ladybird beetles (Coccinellidae): factors shaping their numerical response. Oecologia 90: 238-245.

Hemptinne J.-L., Lognay G., Doumbia M. \& Dixon A.F.G. 2001: Chemical nature and persistence of the oviposition deterring pheromone in the tracks of the larvae of the two spot ladybird, Adalia bipunctata (Coleoptera: Coccinellidae). Chemoecology 11: 43-47.

Phillips T.W. \& Strand M.R. 1994: Larval secretions and food odors affect orientation in female Plodia interpunctella. Entomol. Exp. Appl. 71: 185-192.

RŮŽIČKA Z. 1994: Oviposition-deterring pheromone in Chrysopa oculata (Neuroptera: Chrysopidae). Eur. J. Entomol. 91: 361-370.

RŨŽIČKA Z. 1997a: Persistence of the oviposition-deterring pheromone in Chrysopa oculata (Neur.: Chrysopidae). Entomophaga 42: 109-114.

RŮŽǏ̌KA Z. 1997b: Recognition of oviposition-deterring allomones by aphidophagous predators (Neuroptera: Chrysopidae, Coleoptera: Coccinellidae). Eur. J. Entomol. 94: 431-434.

RƯŽ̌čcKA Z. 2001: Oviposition responses of aphidophagous coccinellids to tracks of coccinellid (Coccinellidae) and chrysopid (Chrysopidae) larvae. Eur. J. Entomol. 98: 183-188.

RŮŽIČKA Z. \& ZEMEK R. in press: Effects of conspecific and heterospecific larval tracks on mobility and searching patterns of Cycloneda limbifer females (Coleoptera: Coccinellidae). In: Proc. 8th Int. Symp. Ecology of Aphidophaga. Kluwer Academic Publishers, The Netherlands.

SALT G. 1934: Experimental studies in insect parasitism II. Superparasitism. Proc. R. Soc. London, Ser. B 114: 455-476.

Yasuda H., Takagi T. \& Kogi K. 2000: Effects of conspecific and heterospecific larval tracks on the oviposition behaviour of the predatory ladybird Harmonia axyridis (Coleoptera: Coccinellidae). Eur. J. Entomol. 97: 551-553.

Received January 14, 2002; revised September 30, 2002; accepted October 9, 2002 